\title{
PERANCANGAN METODE INTERNAL MODEL CONTROL 2 DEGREE OF FREEDOM (IMC 2 DOF) UNTUK PENGENDALIAN MODEL SHELL HEAVY OIL FRACTIONATOR (SHOF)
}

\author{
Fatamorgana Surgani*), Budi Setiyono, dan Sumardi \\ Departemen Teknik Elektro, Universitas Diponegoro \\ Jl. Prof. Sudharto, SH, Kampus UNDIP Tembalang, Semarang 50275, Indonesia \\ ${ }^{*}$ Email: surgani.fatamorgana@gmail.com
}

\begin{abstract}
Abstrak
Shell Heavy Oil Fractionator (SHOF) adalah jenis kolom distilasi yang digunakan untuk memisahkan heavy oil mentah menjadi produk-produk yang diinginkan berdasarkan perbedaan titik didih dari masing-masing produk tersebut. Perancangan kendali pada SHOF memiliki beberapa kendala yang disebabkan oleh non-linearitas pada proses, interaksi multivariabel, adanya waktu tunda (dead time) yang panjang, dan adanya gangguan. Berdasarkan hal tersebut, dibutuhkan metode kendali yang mampu membuat respon sistem mengikuti perubahan set point dan meredam gangguan, sehingga keluaran komposisi produk sesuai dengan yang diharapkan. Pada penelitian ini dibahas perancangan metode IMC 2 DoF untuk pengendalian SHOF MIMO 3x3 terdesentralisasi dalam bentuk fungsi alih first order plus dead time (FOPDT), hal ini dikarenakan metode IMC 2 DoF merupakan salah satu jenis metode kendali modern yang mampu mengendalikan plant multivariabel dan meredam gangguan yang ada. Tuning parameter filter pada pengendali ini menggunakan empat metode tuning parameter filter IMC. Interaksi antar subsistem dikurangi dengan menerapkan metode Relative Gain Array dan melakukan decoupling. Berdasarkan seluruh pengujian yang telah dilakukan, pengendali IMC 2 DoF menggunakan decoupling metode tuning parameter filter Rivera memiliki jumlah nilai IAE terbaik dibandingkan dengan ketiga metode tuning lainnya dengan nilai IAE 93,9585 pada respon $\mathrm{y}_{1}, 40,0476$ pada respon $\mathrm{y}_{2}$, dan 0,0102 pada respon $\mathrm{y}_{3}$.
\end{abstract}

Kata kunci: Shell Heavy Oil Fractionator (SHOF), IMC 2 DoF, tuning, decoupling

\begin{abstract}
Shell Heavy Oil Fractionator (SHOF) is a of distillation column type used to separate crude oil into desired products based on the difference in the boiling point of each product. The design of control on SHOF has several constraints, it caused by non-linearity of the process, mulrivariable interactions, long dead time, and disturbances. It needs the control method that make the system response track the set point and eliminate the disturbances. This research is -designed of IMC 2 DoF method for controlling SHOF with 3x3 MIMO decentralized in the form of First Order Plus Dead Time (FOPDT) transfer function, it because the method of IMC 2 DoF is a modern control method that can control the multivariable plant and eliminate the disturbances. Filter parameters tuned with four methods of tuning IMC filter parameters. The interaction between subsystems is reduced by applying the Relative Gain Array method and decoupling. Based on test, IMC 2 DoF controller used decoupling method of parameter filter tuning of Rivera has the best has the best number of IAE values compared to the other three tuning methods with IAE value of 93.9585 at $y_{1}, 40,0476$ at $y_{2}$, and 0,0102 at $y_{3}$.
\end{abstract}

Keywords: Shell Heavy Oil Fractionator (SHOF), IMC 2 DoF, tuning, decoupling

\section{Pendahuluan}

Shell Heavy Oil Fractionator (SHOF) adalah jenis kolom distilasi yang digunakan untuk memisahkan heavy oil mentah menjadi produk-produk yang diinginkan berdasarkan perbedaan titik didih dari masing-masing produk tersebut. Heavy oil akan dipisahkan, dididihkan menjadi uap dan uap tersebut diembunkan secara kondensasi sehingga didapatkan hasil distilasi [1]. Perancangan kendali pada SHOF memiliki beberapa kendala yang disebabkan oleh non-linearitas pada proses, interaksi multivariabel, adanya waktu tunda (dead time) yang panjang, dan adanya gangguan. Berdasarkan hal tersebut, dibutuhkan suatu metode kendali modern yang mampu mengendalikan respon sistem untuk mengikuti perubahan set point dan meredam atau mengeliminasi gangguan, sehingga keluaran komposisi produk dan suhu sesuai dengan yang diharapkan. Pada penelitian ini dibahas perancangan metode IMC 2 DoF untuk pengendalian SHOF MIMO $3 \times 3$ terdesentralisasi dalam bentuk fungsi alih first order plus dead time (FOPDT), hal ini dikarenakan metode IMC 2 DoF merupakan salah satu 
jenis metode kendali modern yang mampu mengendalikan plant multivariabel dan meredam gangguan yang ada. Metode tuning parameter filter kendali IMC yang dibandingkan adalah Rivera, Chien \& Fruehauf, Lee et al, dan RC.Panda [2][3]Interaksi antar subsistem dikurangi dengan menerapkan metode Relative Gain Array dan melakukan decoupling, sehingga sistem dapat diubah menjadi tiga buah Single Input Single Output (SISO) [4]. Analisis perbandingan kinerja sistem kendali IMC 2 DoF dengan empat metode empiris tuning parameter filter pengendali IMC tersebut berdasarkan nilai IAE.

\section{Metode}

\subsection{Shell Heavy Oil Fractionator (SHOF)}

Kolom fraksinator pada SHOF ditunjukkan oleh Gambar 1 [1]. Berdasarkan kolom fraksinator seperti terlihat pada Gambar 1, heavy oil dialirkan melalui bagian bawah fraksinator yang sebelumnya telah dipanaskan sehingga telah dalam bentuk uap. Selanjutnya di dalam fraksinator heavy oil diproses untuk mendapatkan tiga jenis produk yang dialirkan pada sisi kanan fraksinator bagian atas, tengah, dan bawah dengan satuan alirannya kmol/menit. Spesifikasi produk untuk bagian atas dan tengah ditentukan berdasarkan nilai ekonomis serta pengoperasian atau pengendaliannya, sedangkan produk untuk bagian bawah spesifikasinya tidak ditentukan, tapi ada kendala operasi pada suhu di bagian bawah kolom.

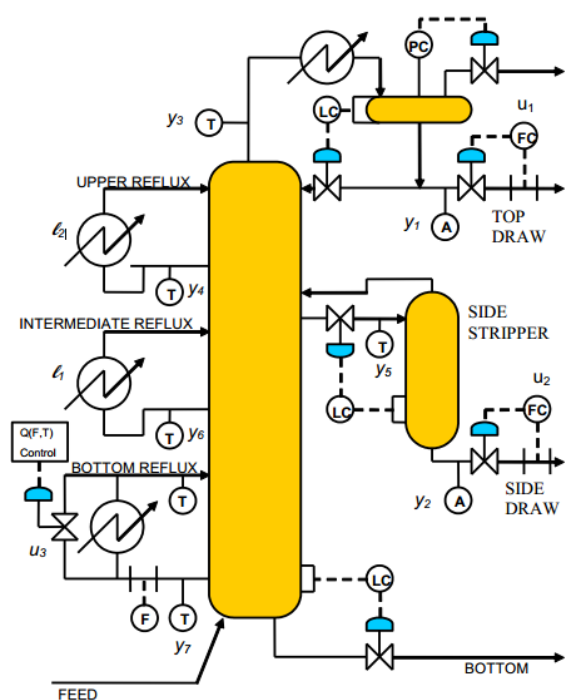

Gambar 1. Sistem kolom Shell Heavy Oil Fractionator

Pada sisi kiri fraksinator terdapat tiga buah refluks uap yaitu bagian atas (upper reflux), tengah (intermediate reflux), dan bawah (bottom reflux) yang berfungsi untuk mengalirkan panas sehingga terjadi pemisahan produk yang diinginkan. Refluks bagian bawah memiliki pengatur entalpi, yang tujuannya adalah untuk mengatur pemindahan panas dalam loop dengan mengatur pembentukan uap [1]. Refluks bagian atas dan tengah digunakan untuk pengambilan panas pada bagian atas dan bagian tengah kolom fraksinator. Kedua refluks tidak dikendalikan secara terpisah sehingga suhu campurannya tidak dapat diatur, kedua besaran ini dapat dianggap sebagai gangguan bagi sistem[1]. Variabel input yang dimanipulasi adalah top draw $\left(\mathrm{u}_{1}\right)$, side draw $\left(\mathrm{u}_{2}\right)$, serta bottom reflux duty $\left(\mathrm{u}_{3}\right)$. Variabel output yang dikendalikan adalah komposisi produk $\left(\mathrm{y}_{1}\right)$, komposisi produk tengah $\left(\mathrm{y}_{2}\right)$ serta suhu reboiler $\left(\mathrm{y}_{3}\right)$. Intermediate reflux duty $\left(\mathrm{d}_{1}\right)$ dan upper reflux duty $\left(\mathrm{d}_{2}\right)$ akan dianggap sebagai variable input gangguan terhadap plant.

Pada penelitian ini, SHOF yang digunakan adalah model SHOF model David M. Preet dan Carlos E. Gracia. Fungsi alih SHOF tersebut ditunjukkan oleh persamaan (1) [1]

$$
\begin{aligned}
& {\left[\begin{array}{l}
\mathrm{Y}_{1} \\
\mathrm{Y}_{2} \\
\mathrm{Y}_{7}
\end{array}\right] }=\left[\begin{array}{ccc}
\frac{4.05 e^{-27 s}}{50 s+1} & \frac{1.77 e^{-28 s}}{60 s+1} & \frac{5.88^{-27 s}}{50 s+1} \\
\frac{5.39^{-18 s}}{50 s+1} & \frac{5.72^{-14 s}}{60 s+1} & \frac{6.90^{-15 s}}{40 s+1} \\
\frac{4.38^{-20 s}}{33 s+1} & \frac{4.42^{-22 s}}{44 s+1} & \frac{7.20}{19 s+1}
\end{array}\right]\left[\begin{array}{l}
\mathrm{U}_{1} \\
\mathrm{U}_{2} \\
\mathrm{U}_{3}
\end{array}\right] \\
&+\left[\begin{array}{cc}
\frac{1,20 e^{-27 s}}{45 s+1} & \frac{1,44 e^{-27 s}}{40 s+1} \\
\frac{1,52 e^{-15 s}}{25 s+1} & \frac{1,83 e^{-15 s}}{20 s+1} \\
\frac{1,14}{27 s+1} & \frac{1,26}{32 s+1}
\end{array}\right]\left[\begin{array}{l}
\mathrm{d}_{1} \\
\mathrm{~d}_{2}
\end{array}\right]
\end{aligned}
$$

Tujuan kontrol dan Tujuan Ekonomi pada Shell Heavy Oil Fractionator (SHOF) adalah sebagai berikut[1][6][7]:

Tujuan kontrol dari proses SHOF yaitu:

1. Menjaga $y_{1}$ pada pada $0,0 \pm 0,005$ keadaan steady

2. Menjaga $y_{2}$ pada pada $0,0 \pm 0,005$ keadaan steady

3. Menolak masukan gangguan pada $d_{1}$ dan $d_{2}$ dimana dapat bervariasi antara $-0,5$ dan 0,5

4. Tujuan ekonomi dari proses SHOF yaitu memaksimalkan uap (steam) pada generator uap (memaksimalkan heat removal) pada sirkulasi reflux bagian bawah $u_{3}$. Memaksimalkan uap dilakukan dengan membuat $u_{3}$ sekecil mungkin.

Batasan-batasan (constraint) pengontrolan yang dimiliki SHOF yaitu[1][6][7]:

1. Aliran atas dan aliran tengah memiliki batas atas dan batas bawah (hard bounds) :

$-0,5 \leq u_{1} \leq 0,5$

$-0,5 \leq u_{2} \leq 0,5$

2. Reflux duty bawah memiliki batas :

$-0,5 \leq u_{3} \leq 0,5$

3. $y_{1}$ dan $y_{2}$ harus dikontrol antara $-0,5$ dan 0,5 selama terjadi gangguan.

4. $y_{3}$ memiliki nilai minimum yaitu $-0,5$.

\subsection{Sistem Kendali MIMO \\ 2.1.1. Sistem MIMO Terdesentralisasi}

Sistem kontrol terdesentralisasi digunakan secara luas dalam dunia industri karena struktur sistem yang mudah 
didesain, kesederhanaan dalam pengadaan perangkat keras, mudah untuk melakukan tuning parameter yang digunakan, dan sistem bersifat fleksibel dalam operasi serta perbaikan[8][9].

Dalam praktiknya untuk sistem MIMO dengan jumlah n variabel yang dikontrol dan $\mathrm{n}$ variabel yang dimanipulasi akan menghasilkan kemungkinan konfigurasi sebanyak $n$ ! [5]. Sehingga struktur sistem MIMO 3x3 memiliki 3! atau enam kemungkinan konfigurasi kontrol yang tersedia. Struktur 1-1/2-2/3-3 sistem MIMO terdesentralisasi ditunjukkan oleh Gambar 2[10].

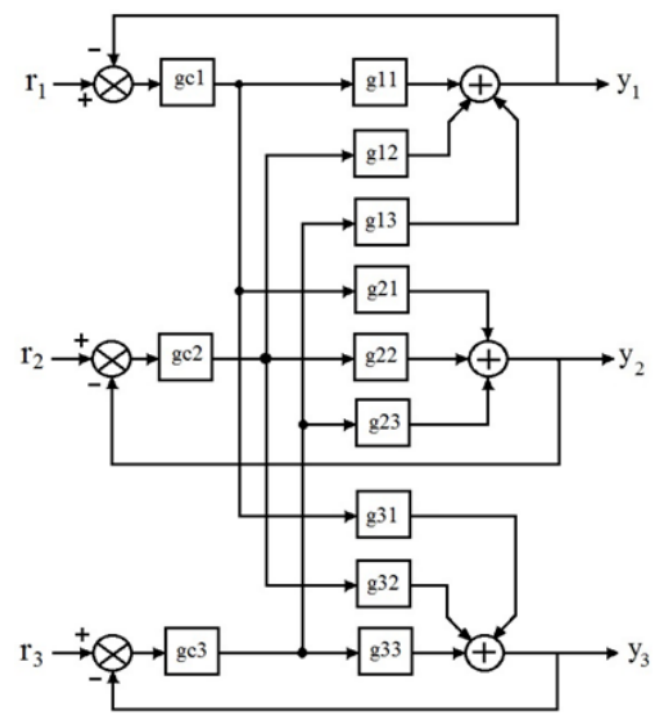

Gambar 2. Struktur kontrol terdesentralisasi MIMO 3x3

\subsubsection{Relative Gain Array (RGA)}

RGA berfungsi untuk menghitung interaksi masukankeluaran pada sistem kendali MIMO dan menentukan pasangan masukan dan keluaran kendali MIMO terdesentralisasi yang akan digunakan [11]. RGA pada sistem $3 \times 3$ dirumuskan pada persamaan 2 [12].

$R G A=K . \otimes\left(K^{-1}\right)^{T}$

Untuk menentukan pasangan-pasangan variabel masukan dan keluaran suatu proses multivariable dengan relative gain array seperti pada persamaan (3) dapat digunakan pairing rule yang sebagai berikut [13][4] :

- Pairing rule 1: Pilihlah pasangan yang menyusun kembali sistem, dengan pilihan pasangan diagonal, memiliki matriks RGA mendekati identitas pada saat frekuensi berada pada sekitar bandwidth lingkar tertutup.

- Pairing rule 2 : Hindari (jika memungkinkan) pasangan negatif pada elemen RGA steady state.

Hasil perhitungan RGA pada SHOF sebagai berikut.
$R G A=\left[\begin{array}{ccc}2,08 & -0,73 & -0,35 \\ 3,42 & 0,94 & -3,36 \\ -4,50 & 0,79 & 4,71\end{array}\right]$

Berdasarkan pairing rule dan hasil perhitungan nilai RGA, didapatkan konfigurasi pada SHOF yakni 1-1/2-2/3-3, dimana top draw $\left(\mathrm{u}_{1}\right)$ akan mempengaruhi keluaran komposisi produk bagian atas $\left(\mathrm{y}_{1}\right)$, pengendalian side draw $\left(\mathrm{u}_{2}\right)$ akan mempengaruhi keluaran komposisi produk bagian tengah $\left(\mathrm{y}_{2}\right)$, dan pengendalian bottom reflux duty $\left(\mathrm{u}_{3}\right)$ akan mempengaruhi keluaran suhu reboiler bawah $\left(\mathrm{y}_{3}\right)$.

\subsection{IMC 2 DoF pada SHOF}

Pengendali IMC 2 DoF merupakan metode kendali modern yang mampu mengendalikan respon sistem untuk mengikuti perubahan set point dan meredam atau mengeliminasi gangguan yang ada. Struktur IMC 2 DoF dengan decoupling ditunjukkan oleh Gambar 3[5].

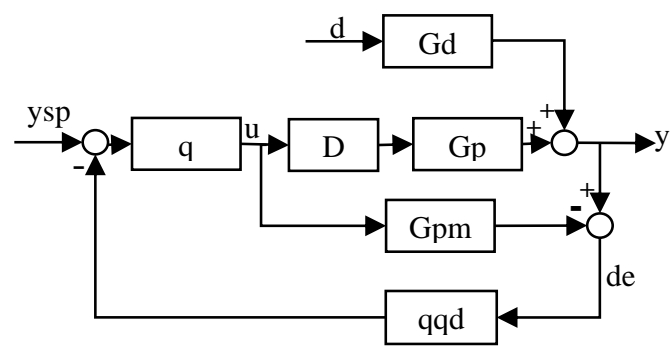

Gambar 3. Struktur IMC 2 Dof dengan Decoupling

Berdasarkan Gambar 3, parameter pada struktur IMC 2 DoF meliputi fungsi alih pengendali set point tracking (q), fungsi alih pengendali disturbance rejections $\left(\mathrm{qq}_{\mathrm{d}}\right)$, fungsi alih proses $\left(G_{p}\right)$, fungsi alih model proses $\left(G_{p m}\right)$, fungsi alih gangguan $\left(\mathrm{G}_{\mathrm{d}}\right)$, set point variabel output yang dikendalikan $\left(\mathrm{y}_{\mathrm{sp}}\right)$, variabel output yang dikendalikan $(\mathrm{y})$, variabel input yang dimanipulasi / controller output (u), variabel input gangguan (d), variabel estimasi pengaruh gangguan (de), dan variabel decoupling (D) [5].

Metode pengendalian SHOF yang digunakan pada sistem ini adalah metode IMC 2 DoF. Fungsi alih dari SHOF tersebut ditunjukkan oleh persamaan (1).

Fungsi alih proses $\left(G_{p}\right)$ dalam bentuk FOPDT dapat dituliskan dengan menggunakan persamaan (3) [1][7].

$$
\begin{aligned}
G_{p}(s) & =\left[\begin{array}{lll}
G_{p 11}(s) & G_{p 12}(s) & G_{p 13}(s) \\
G_{p 21}(s) & G_{p 22}(s) & G_{p 23}(s) \\
G_{p 31}(s) & G_{p 32}(s) & G_{p 33}(s)
\end{array}\right] \\
& =\left[\begin{array}{lll}
\frac{4,05 e^{-27 s}}{50 s+1} & \frac{1,77 e^{-28 s}}{60 s+1} & \frac{5,88 e^{-27 s}}{50 s+1} \\
\frac{5,39 e^{-18 s}}{50 s+1} & \frac{5,72 e^{-14 s}}{60 s+1} & \frac{6,90 e^{-15 s}}{40 s+1} \\
\frac{4,38 e^{-20 s}}{33 s+1} & \frac{4,42 e^{-22 s}}{44 s+1} & \frac{7,20}{19 s+1}
\end{array}\right]
\end{aligned}
$$


Fungsi alih gangguan $\left(\mathrm{G}_{\mathrm{d}}\right)$ dalam bentuk FOPDT dapat dituliskan dengan menggunakan persamaan (4) [1][7].

$\mathrm{G}_{\mathrm{d}}=\left[\begin{array}{ll}\mathrm{G}_{\mathrm{d} 11} & \mathrm{G}_{\mathrm{d} 12} \\ \mathrm{G}_{\mathrm{d} 21} & \mathrm{G}_{\mathrm{d} 22} \\ \mathrm{G}_{\mathrm{d} 31} & \mathrm{G}_{\mathrm{d} 32}\end{array}\right]==\left[\begin{array}{cc}\frac{1,20 e^{-27 s}}{45 s+1} & \frac{1,44 e^{-27 s}}{40 s+1} \\ \frac{1,52 e^{-15 s}}{25 s+1} & \frac{1,83 e^{-15 s}}{20 s+1} \\ \frac{1,14}{27 s+1} & \frac{1,26}{32 s+1}\end{array}\right]$

Fungsi alih model proses $\left(\mathrm{G}_{\mathrm{pm}}\right)$ dalam bentuk FOPDT pada sistem AIMC 2 DoF dapat dituliskan dengan menggunakan persamaan (5) [16].

$$
\begin{aligned}
\mathrm{G}_{\mathrm{pm}} & =\operatorname{diag} \cdot\left[\begin{array}{ccc}
\mathrm{G}_{\mathrm{p} 11} & \mathrm{G}_{\mathrm{p} 22} & \mathrm{G}_{\mathrm{p} 33}
\end{array}\right] \\
& =\left[\begin{array}{ccc}
\frac{4.05 e^{-27 s}}{50 s+1} & 0 & 0 \\
0 & \frac{5.72 e^{-14 s}}{60 s+1} & 0 \\
0 & 0 & \frac{7.20}{19 s+1}
\end{array}\right]
\end{aligned}
$$

Fungsi alih model proses $\left(\mathrm{G}_{\mathrm{pm}}\right)$ dapat dibagi menjadi dua bagian, yaitu bagian yang dapat diinversikan $\left(\mathrm{G}_{\mathrm{pm}}{ }^{-}\right)$dan bagian yang tidak dapat diinversikan $\left(\mathrm{G}_{\mathrm{pm}}{ }^{+}\right)$, yang dapat dituliskan dengan persamaan (6), (7) dan (8) [17].

$\mathrm{G}_{\mathrm{pm} 11}=\mathrm{G}_{\mathrm{pm} 11}{ }^{-} \cdot \mathrm{G}_{\mathrm{pm} 11}{ }^{+}=\frac{4.05}{50 s+1} \cdot \frac{1-\frac{27 \mathrm{~s}}{2}}{1+\frac{27 \mathrm{~s}}{2}}$

$G_{p m 22}=G_{p m 22}{ }^{-} \cdot G_{p m 22}{ }^{+}=\frac{5,72}{60 s+1} \cdot \frac{1-\frac{14 s}{2}}{1+\frac{14 s}{2}}$

$\mathrm{G}_{\mathrm{pm} 33}=\mathrm{G}_{\mathrm{pm} 22}{ }^{-} \cdot \mathrm{G}_{\mathrm{pm} 22}{ }^{+}=\frac{7.20}{19 s+1}$

Fungsi alih pengendali set point tracking $(q(s))$ pada IMC 2 DoF dapat dirancang dengan menggunakan persamaan (9) [16].

$$
\begin{aligned}
& \mathrm{q}(\mathrm{s})=\operatorname{diag} .\left[\begin{array}{lll}
q_{1}(s) & q_{2}(s) & q_{3}(s)
\end{array}\right] \\
& =\left[\begin{array}{ccc}
\text { inv } \cdot\left(\mathrm{G}_{\mathrm{pm} 11}\right) \cdot \mathrm{f}_{1} & 0 & 0 \\
0 & \text { inv. }\left(\mathrm{G}_{\mathrm{pm} 22}{ }^{-}\right) \cdot \mathrm{f}_{2} & 0 \\
0 & 0 & \text { inv. }\left(\mathrm{G}_{\mathrm{pm} 22}{ }^{-}\right) \cdot \mathrm{f}_{3}
\end{array}\right] \text { (9) } \\
& f=\frac{1}{\tau_{c} s+1}
\end{aligned}
$$

Berdasarkan persamaan (6) hingga persamaan (10) fungsi alih pengendali set point tracking $(q(s))$ dapat dituliskan dengan persamaan (11), (12), dan (13).

$$
\begin{aligned}
& \mathrm{q}_{1}(\mathrm{~s})=\frac{50 \mathrm{~s}+1}{4.05\left(\tau_{\mathrm{c} 1} \mathrm{~s}+1\right)} \\
& \mathrm{q}_{2}(\mathrm{~s})=\frac{60 \mathrm{~s}+1}{5.72\left(\tau_{\mathrm{c} 2} \mathrm{~s}+1\right)} \\
& \mathrm{q}_{3}(\mathrm{~s})=\frac{19 \mathrm{~s}+1}{7.20\left(\tau_{\mathrm{c} 3} \mathrm{~s}+1\right)}
\end{aligned}
$$

Fungsi alih pengendali disturbance rejection $\left(\mathrm{qq}_{\mathrm{d}}\right)$ pada IMC 2 DoF dapat dirancang dengan menggunakan persamaan (14) dan (15) [18].

$$
\begin{aligned}
& \mathrm{qq}_{\mathrm{d}}(\mathrm{s})=\text { diag. }\left[\begin{array}{lll}
q q_{\mathrm{d} 1} & q q_{\mathrm{d} 2} & \mathrm{qq}_{\mathrm{d} 3}
\end{array}\right] \\
& =\left[\begin{array}{ccc}
q q d_{1}(\mathrm{~s}) \cdot \frac{\alpha_{1} \mathrm{~s}+1}{\tau_{\mathrm{c} 1} \mathrm{~s}+1} & 0 & 0 \\
0 & q q d_{2}(\mathrm{~s}) \cdot \frac{\alpha_{2} \mathrm{~s}+1}{\tau_{\mathrm{c} 2} \mathrm{~s}+1} & 0 \\
0 & 0 & q q d_{3}(\mathrm{~s}) \cdot \frac{\alpha_{3} \mathrm{~s}+1}{\tau_{\mathrm{c} 3} \mathrm{~s}+1}
\end{array}\right]
\end{aligned}
$$

$\propto=\frac{\left(1-\frac{\tau_{\mathrm{c}}}{\tau}\right)^{2}-\mathrm{e}^{\frac{\theta}{\tau}}}{-\mathrm{e}^{\frac{\theta}{\tau}}} . \tau$

Metode tuning parameter filter $\left(\tau_{\mathrm{c}}\right)$ pengendali IMC pada fungsi alih pengendali set point tracking (q(s)) dan fungsi alih pengendali disturbance rejections $\left(\mathrm{qq}_{\mathrm{d}}(s)\right)$ ditunjukkan oleh Tabel 1[2] [3].

Tabel 1. Metode tuning parameter filter IMC

\begin{tabular}{cc}
\hline Metode Tuning Parameter Filter & Syarat Tuning $\boldsymbol{\tau}_{\mathbf{c}}$ \\
\hline IMC & $\tau_{\mathrm{c}}>0,8 \theta$ \\
Rivera & $\tau>\tau_{\mathrm{c}}>\theta$ \\
Chien \& Fruehauf & $\tau_{\mathrm{c}} \geq 0,1 \tau$ \\
Lee et al & $\tau_{c}=\max (0,2 \tau, 1,7 \theta)$ \\
RC. Panda &
\end{tabular}

Berdasarkan nilai $\theta$ dan $\tau$ pada fungsi alih model proses $\mathrm{G}_{\mathrm{pm} 11}, \mathrm{G}_{\mathrm{pm} 22}$ dan $\mathrm{G}_{\mathrm{pm} 33}$, syarat tuning parameter filter $\left(\tau_{\mathrm{c}}\right)$ pada Tabel 1 , dan uji empiris yang dilakukan pada sistem, nilai tuning parameter filter $\left(\tau_{\mathrm{c}}\right)$ pada fungsi alih pengendali set point tracking $(q(s))$ dan pengendali disturbance rejections $\left(\mathrm{qq}_{\mathrm{d}}(s)\right)$ pada ditunjukkan oleh Tabel 2.

\begin{tabular}{|c|c|c|c|}
\hline \multirow[t]{2}{*}{ Metode } & \multicolumn{3}{|c|}{$\begin{array}{c}\text { Fungsi Alih } \\
\text { Pengendali Set point Tracking }\end{array}$} \\
\hline & $\mathbf{q}_{1}(s)$ & $\mathbf{q}_{2}(s)$ & $\mathbf{q}_{3}(s)$ \\
\hline \multirow{2}{*}{ Rivera } & $50 s+1$ & $60 s+1$ & $19 s+1$ \\
\hline & $\overline{101,25 s+4,05}$ & $\overline{131,56 s+5,72}$ & $\overline{0,72 s+7,2}$ \\
\hline \multirow{2}{*}{$\begin{array}{l}\text { Chien \& } \\
\text { Fruehauf }\end{array}$} & $50 s+1$ & $60 s+1$ & $19 s+1$ \\
\hline & $\begin{array}{c}\overline{113,4 s+4,05} \\
50 s+1\end{array}$ & $\begin{array}{c}\overline{102,96 s+5,72} \\
60 s+1\end{array}$ & $\begin{array}{c}1,296 s+7,2 \\
19 s+1\end{array}$ \\
\hline Lee et al & $\begin{array}{c}\overline{109,35 s+4,05} \\
50 s+1\end{array}$ & $\begin{array}{c}\overline{120,126 s+5,72} \\
60 s+1\end{array}$ & $\begin{array}{c}\overline{14,4 s+7,2} \\
19 s+1\end{array}$ \\
\hline RC. Panda & $\overline{185,895 s+4,05}$ & $\overline{136,136 s+5,72}$ & $\overline{27,36 s+7,2}$ \\
\hline
\end{tabular}

Tabel 2. Nilai tuning parameter filter $\left(\tau_{c}\right)$ kelima metode empiris

\begin{tabular}{cccc}
\hline Metode Tuning & \multicolumn{3}{c}{ Nilai Tuning } \\
Parameter Filter IMC & $\boldsymbol{\tau}_{\mathbf{c} 1}$ & $\boldsymbol{\tau}_{\mathbf{c} 2}$ & $\boldsymbol{\tau}_{\mathbf{c} 2}$ \\
\hline Rivera & 25 & 23 & 0,1 \\
Chien \& Fruehauf & 28 & 18 & 0,18 \\
Lee et al & 27 & 21 & 2 \\
RC. Panda & 45,9 & 23,8 & 3,8 \\
\hline
\end{tabular}

Substitusikan nilai tuning parameter filter $\left(\tau_{\mathrm{c} 1}, \tau_{\mathrm{c} 2}, \tau_{\mathrm{c} 3}\right)$ yang ditunjukkan pada Tabel 2 ke dalam persamaan (13), (14), dan (15) sehingga fungsi alih pengendali set point tracking $(q(s))$ dapat ditunjukkan oleh Tabel 3.

Tabel 3. Fungsi alih pengendali set point tracking $(\mathbf{q}(\mathbf{s}))$ berdasarkan nilai tuning parameter filter $\left(\boldsymbol{\tau}_{c}\right)$ 
Substitusikan nilai tuning parameter filter $\left(\tau_{\mathrm{c} 1}, \tau_{\mathrm{c} 2}, \tau_{\mathrm{c} 3}\right)$ pada Tabel 2, fungsi alih pengendali set point tracking $\left(\mathrm{q}_{1}, q_{2}, q_{3}\right)$ pada Tabel 3 , serta nilai waktu mati $(\theta)$ dan konstanta waktu $(\tau)$ pada fungsi alih model proses $G_{p m 11}$, $G_{\text {pm22 }}$, dan $G_{\text {pm33 }}$ ke dalam persamaan (16) dan persamaan
(17), sehingga fungsi alih pengendali disturbance rejections $\left(\mathrm{qq}_{\mathrm{d}}\right)$ dapat ditunjukkan oleh Tabel 4.

Tabel 4. Fungsi alih pengendali disturbance rejections $\left(\mathbf{q q}_{\mathbf{d}}(\boldsymbol{s})\right)$ berdasarkan nilai tuning parameter filter $\left(\tau_{\mathbf{c}}\right)$

\begin{tabular}{|c|c|c|c|}
\hline \multirow[t]{2}{*}{ Metode } & \multicolumn{3}{|c|}{$\begin{array}{c}\text { Fungsi Alih } \\
\text { Pengendali Disturbance Rejections }\end{array}$} \\
\hline & $\mathbf{q q}_{\mathrm{d} 1}$ & $\mathbf{q q}_{\mathrm{d} 2}$ & $\mathbf{q q}_{\mathrm{d} 3}$ \\
\hline Piver & $2135,7823 s^{2}+92,7156 s+1$ & $2515,9032 s^{2}+101,932 s+1$ & $3,79 s^{2}+19,1995 s+1$ \\
\hline Nivela & $2531,25 s^{2}+202,5 s+4,05$ & $\overline{3025,88 s^{2}+263,12 s+5,72}$ & $\overline{0,072 s^{2}+1,44 s+7,2}$ \\
\hline Chien \& & $2217,9488 s^{2}+94,359 s+1$ & $2203,1068 s^{2}+96,71845 s+1$ & $6,8076 s^{2}+19,35829 s+1$ \\
\hline Fruehauf & $\begin{array}{c}3175,2 s^{2}+226,8 s+4,05 \\
2191,7262 s^{2}+93,8345 s+1\end{array}$ & $\begin{array}{l}1853,28 s^{2}+205,92 s+5,72 \\
2395,536 s^{2}+99,9256 s+1\end{array}$ & $\begin{array}{c}0,23328 s^{2}+2,592 s+7,2 \\
72 s^{2}+22,7895 s+1\end{array}$ \\
\hline Lee et al & $\begin{array}{c}2952,45 s^{2}+218,7 s+4,05 \\
2490,2 s^{2}+99,804 s+1\end{array}$ & $\begin{array}{l}\overline{2522,52 s^{2}+240,24 s+5,72} \\
2562,3 s^{2}+102,705 s+1\end{array}$ & $\begin{array}{r}\overline{28,8 s^{2}+28,8 s+7,2} \\
129,96 s^{2}+25,84 s+1\end{array}$ \\
\hline RC. Panda & $8532,5805 s^{2}+371,79 s+4,05$ & $3240,0368 s^{2}+272,272 s+5,72$ & $\overline{103,968 s^{2}+54,72 s+7,2}$ \\
\hline
\end{tabular}

Tujuan utama dari decoupling adalah untuk mengurangi bahkan menghilangkan efek interaksi antar loop tertutup. Metode kontrol decoupling ini dikembangkan oleh Zalkind dan Luyben [13]. Struktur kontrol decoupling sistem SHOF ditunjukkan oleh Gambar 4[14].

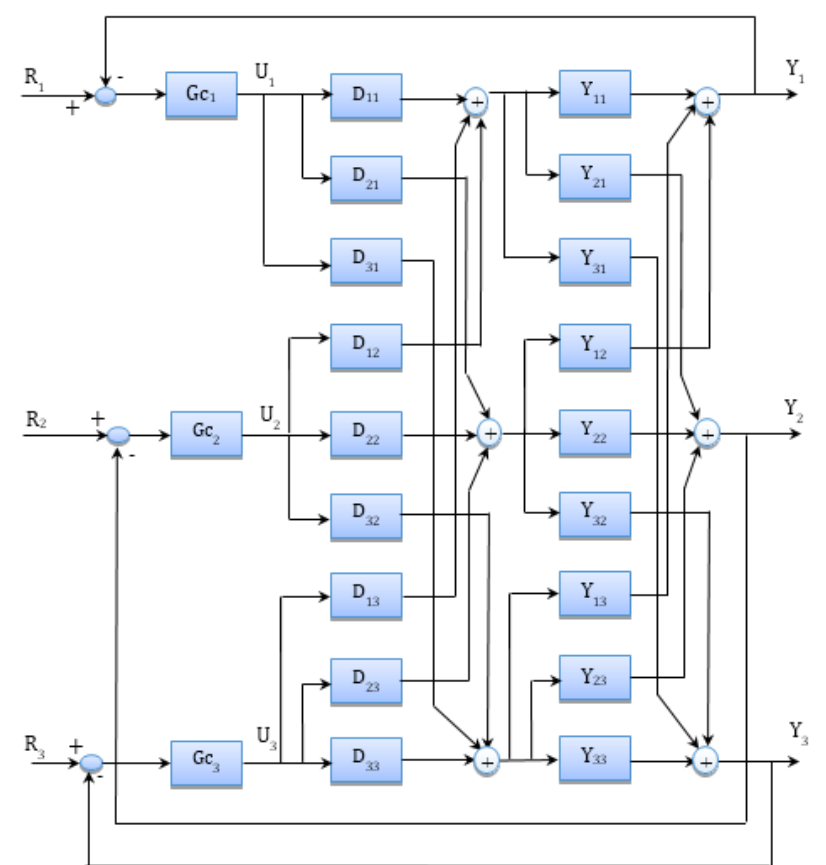

Gambar 4. Multivariable decoupling system

Pada struktur Internal Model Control (IMC), decoupler (D) di tempatkan antara fungsi alih model $\left(\mathrm{G}_{\mathrm{pm}}\right)$ dengan fungsi alih plant $\left(G_{p}\right)$ seperti gambar $4[5][15]$.

Untuk sistem SHOF, orde yang digunakan termasuk ke dalam orde tinggi, yakni $3 \times 3$. Oleh karena itu, untuk menghitung elemen decoupling pada sistem ini masingmasing transfer function $\mathrm{G}(\mathrm{s})$ dilakukan pendekatan dengan masing-masing nilai gain $\mathrm{K}$ serta mengabaikan efek waktu tunda[13].

Dari persamaan setiap pasangan variabel masukan dan keluaran, diperoleh dekopler berikut :

$$
\begin{aligned}
& D_{11}=D_{22}=D_{33}=1 \\
& D_{12}=\frac{K_{32} \cdot K_{13}-K_{12} \cdot K_{33}}{K_{11} \cdot K_{33}-K_{31} \cdot K_{13}}=\frac{13,246}{3,406}=3,8893587033 \\
& D_{13}=\frac{K_{23} \cdot K_{12}-K_{13} \cdot K_{22}}{K_{11} \cdot K_{22}-K_{21} \cdot K_{12}}=-\frac{21,421}{13,626}=-1,5720733614 \\
& D_{21}=\frac{K_{31} \cdot K_{23}-K_{21} \cdot K_{33}}{K_{22} \cdot K_{33}-K_{32} \cdot K_{23}}=-\frac{8,586}{10,686}=0,8034811903 \\
& D_{23}=\frac{K_{23} \cdot K_{11}-K_{13} \cdot K_{21}}{K_{12} \cdot K_{21}-K_{22} \cdot K_{11}}=\frac{-3,7482}{-13,6257}=0,275083115 \\
& D_{31}=\frac{K_{31} \cdot K_{22}-K_{21} \cdot K_{32}}{K_{23} \cdot K_{32}-K_{33} \cdot K_{22}}=-\frac{1,2298}{10,686}=-0,1150851582 \\
& D_{32}=\frac{K_{32} \cdot K_{11}-K_{12} \cdot K_{31}}{K_{13} \cdot K_{31}-K_{33} \cdot K_{11}}=-\frac{10,1484}{3,4056}=-2,9799154334
\end{aligned}
$$

\section{Hasil dan Analisa}

Pengujian pada bagian ini dilakukan dengan memberikan masukan gangguan Intermediate reflux duty $\left(\mathrm{d}_{1}\right)$ dan upper reflux duty $\left(\mathrm{d}_{2}\right)$ masing-masing sebesar $+0,5$ saat $y_{1}, y_{2}$, dan $y_{3}$ telah mencapai set point $+0,5$. Input gangguan yang diberikan berupa gangguan step dan gangguan impuls. Simulasi dijalankan dalam waktu 2000 detik. Pengujian ini berlaku pada sistem tanpa decoupling dan sistem dengan decoupling. Gambar 5 merupakan hasil pengujian menggunakan decoupling terhadap masukan gangguan $d_{1}+0,5$ dan $d_{2}+0,5$.

Perbandingan nilai IAE masing-masing metode tuning parameter filter pada pengujian dapat diliat pada Tabel 5. Berdasarkan Tabel 5, nilai IAE terkecil pada pengujian ini diperoleh menggunakan metode tuning parameter filter Rivera memiliki jumlah nilai IAE terkecil dibandingkan dengan ketiga metode tuning lainnya dengan nilai IAE 
93,9585 pada respon $y_{1}$, 40,0476 pada respon $y_{2}$, dan 0,0102 pada respon $y_{3}$.

Tabel 5. Nilai IAE pengujian masukan gangguan $d_{1} d_{1 a n} d_{2}$ masing-masing sebesar $+0,5$ ketika set point $y_{1}, y_{2}$, dan $y_{3}$ dinaikkan masing-masing sebesar $+0,5$

\begin{tabular}{|c|c|c|c|}
\hline \multirow{2}{*}{$\begin{array}{l}\text { Metode } \\
\text { Tuning } \\
\text { Parameter } \\
\text { Filter }\end{array}$} & \multicolumn{3}{|c|}{$\begin{array}{c}\text { IAE } \\
d_{1}+0,5, \text { dan } d_{2}+0,5 \\
\text { ketika } y_{1}+0,5, y_{2}+0,5, \text { dan } y_{3}+0,5\end{array}$} \\
\hline & $\mathrm{y}_{1}$ & $y_{2}$ & $y_{3}$ \\
\hline Rivera & 93,9585 & 40,0476 & 0,0102 \\
\hline $\begin{array}{l}\text { Chien \& } \\
\text { Fruehauf }\end{array}$ & 105,8815 & 33,2929 & 0,052 \\
\hline Lee et al & 101,8432 & 37,2685 & 4,4241 \\
\hline RC. Panda & 189,0447 & 41,2616 & 13,244 \\
\hline
\end{tabular}

Grafik respon sistem pada Gambar 5, dapat dilihat bahwa pengendali IMC 2 DoF mampu meredam gangguan yaitu Intermediate reflux duty $\left(\mathrm{d}_{1}\right)$ dan upper reflux duty $\left(\mathrm{d}_{2}\right)$, dan mengembalikan respon komposisi produk atas $\left(y_{1}\right)$, komposisi produk tengah $\left(y_{2}\right)$, dan suhu reboiler bawah $\left(\mathrm{y}_{3}\right)$ pada set point yang diberikan.

Pada Gambar 5d, dapat diamati bahwa variabel manipulative laju aliran side draw $\left(\mathrm{u}_{2}\right)$ terhadap masukan gangguan $\mathrm{d}_{1}$ dan $\mathrm{d}_{2}$ masing-masing sebesar $+0,5$ ketika set point $y_{1}, y_{2}$, dan $y_{3}$ masing-masing sebesar $+0,5$ memberikan unjuk kerja yang sangat baik, dengan tidak melebihi batas maksimum $+0,5$ dan batas minimum $-0,5$. Namun Gambar 5a dan 5f menunjukkan laju aliran top draw $\left(\mathrm{u}_{1}\right)$, dan bottom refluks duty $\left(\mathrm{u}_{3}\right)$ memberikan unjuk kerja yang kurang baik, karena melebihi batas batas minimum $-0,5$.

Penambahan decoupling pada sistem MIMO mampu mengurangi interaksi antara pasangan-pasangan masukan dan keluaran, sehingga membuat osilasi respon sistem Gambar 5 menjadi jauh lebih kecil dan sistem lebih cepat menuju kestabilan.

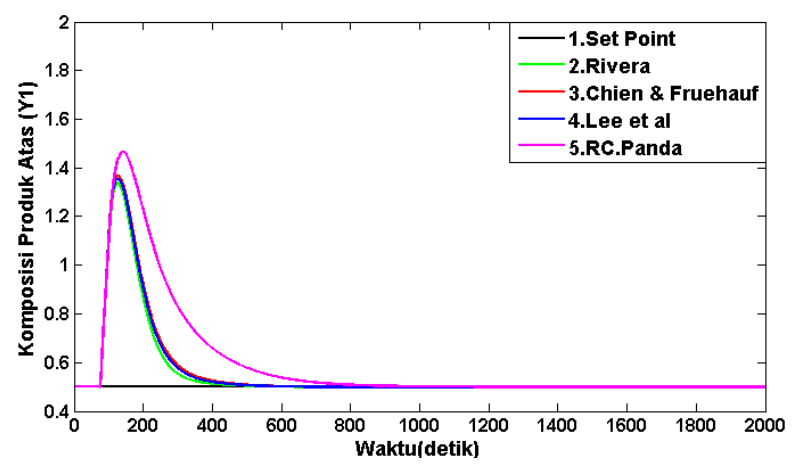

(a) Respon komposisi produk atas $\left(\mathrm{y}_{1}\right)$.

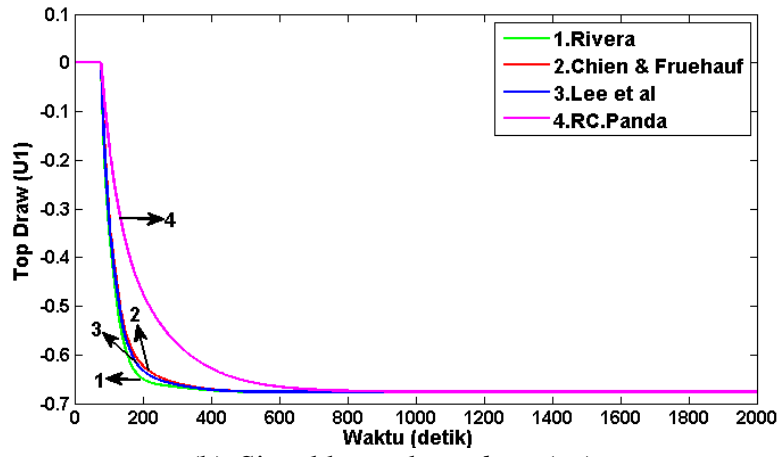

(b) Sinyal kontrol top draw $\left(\mathrm{u}_{1}\right)$.

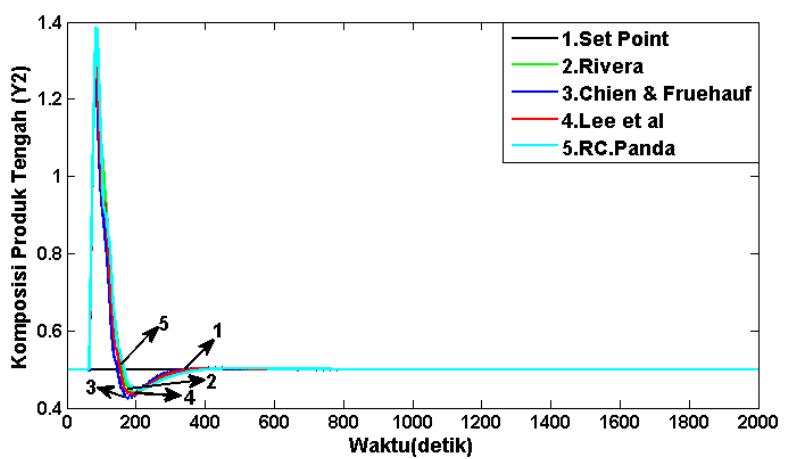

(c) Respon komposisi produk tengah $\left(\mathrm{y}_{2}\right)$.

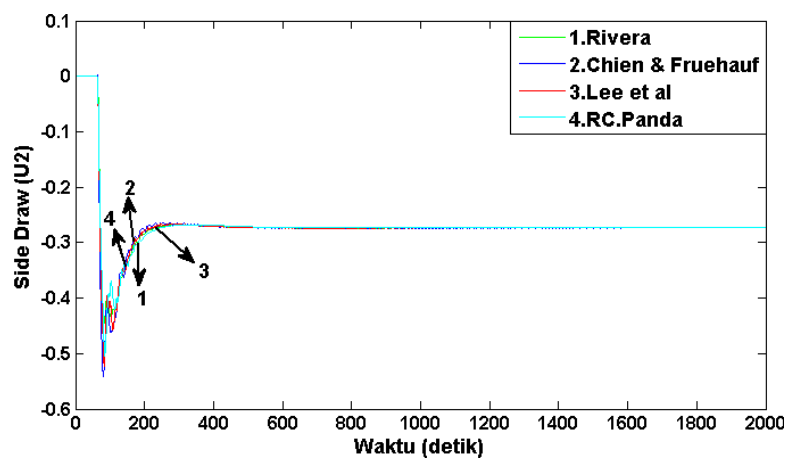

(d) Sinyal 45ontrol side draw $\left(\mathrm{u}_{2}\right)$.

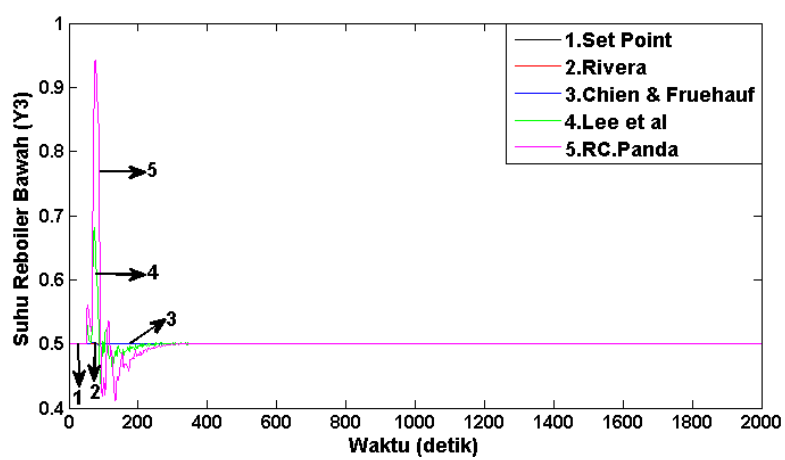

(e) Respon suhu reboiler bawah $\left(\mathrm{y}_{3}\right)$. 


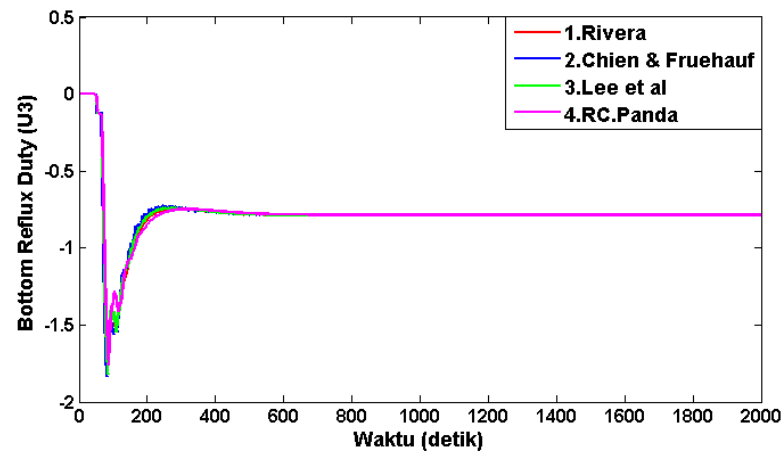

(f) Sinyal 46ontrol bottom reflux duty $\left(\mathrm{u}_{3}\right)$.

Gambar 5. Hasil pengujian terhadap masukan gangguan $d_{1}+0,5$ dan $d_{2}+0,5$, ketika set point $y_{1}+0,5$, $y_{2}+0,5$, dan $y_{3}+0,5$

\section{Kesimpulan}

Berdasarkan pengujian yang telah dilakukan, dapat disimpulkan bahwa pengendali IMC 2 DoF yang digunakan pada SHOF mampu mengendalikan sistem untuk mencapai nilai set point komposisi produk yang diberikan dan mampu meredam gangguan yang masuk pada proses, serta penambahan decoupling pada sistem mampu mengurangi interaksi antara pasangan-pasangan masukan dan keluaran Berdasarkan seluruh pengujian yang telah dilakukan, pengendali IMC 2 DoF menggunakan decoupling metode tuning parameter filter Rivera memiliki jumlah nilai IAE terbaik dibandingkan dengan ketiga metode tuning lainnya dengan nilai IAE 93,9585 pada respon $y_{1}, 40,0476$ pada respon $y_{2}$, dan 0,0102 pada respon $y_{3}$.

\section{Referensi}

[1] D. M.Preet and C. E. Garcia, Fundamental process Control. United States of America: Butterworth, 1988.
[2] Ba. B. Wara, B. Setiyono, and Wahyudi, "Pengontrolan Kolom Distilasi Biner Menggunakan Metode Internal Model Control," Transient, vol. 5, no. 2, pp. 166-172, 2016.

[3] "Controller Design Based on Transient Response Criteria," in Handbook Chapter 12, .

[4] J. Aria, I. Setiawan, and B. Setiyono, "Analisis dan Simulasi Shell Heavy Oil Fractionator ( SHOF ) Menggunakan Metode Kontrol PID,” Transmisi, vol. 13, no. 4, pp. 114-120, 2011.

[5] B. J. Coleman Brosilow, Techniques of Model-Based Control. United States of America: Prentice Hall PTR, 2002.

[6] A. A. Araromi, Dauda Olurotimi and Sulayman, "Gain Scheduling Control Design For Shell Heavy Oil Fractionator Column," Eur. Cent. Res. Train. Dev. UK, vol. 3, no. 1, pp. 13-28, 2015.

[7] R. M.Ansari and Moses, Nonlinear Model-based Process Control Applications in Petroleum Refining, 1st Editio. London: Springer, 2000.

[8] M. Bharathi and C. Selvakumar, "Dynamic Modeling, Simulation and Control of MIMO Systems," Int. J. Comput. Trends Technol., vol. 3, no. 3, pp. 71-84, 2012.

[9] S. Skogestad and I. Postlethwaite, Introduction, Multivariable Feedback Control Analysis and Design, Second Edi. 2001.

[10] A. H. Devikumari and V. Vijayan, "Decentralized PID Controller Design for 3x3 Multivariable System using Heuristic Algorithms," Indian J. Sci. Technol., vol. 8, no. 15, pp. 1-6, 2015.

[11] W. Hu, W. Cai, and G. Xiao, "Relative Gain Array for MIMO Processes Containing Integrators and/or Differentiators," 11th Int. Conf. Control. Autom. Robot. Vis., no. August 2017, pp. 231-235, 2010.

[12] D. E. Seborg, T. F. Edgar, and D. A. Mellichamp, Process Dynamics and Control, Second Edi. United States of America: John Wiley \& Sons, 2004.

[13] M. Safitri, A. Triwiyanto, and Wahyudi, "Perancangan Sistem Kontrol Genetic-Fuzzy Studi Kasus Pada Pengendalian Top And Side End Point Composition dan Bottom Refluksi Temperature Pada Distillation Column," Transmisi, vol. 14, no. 3, pp. 85-90, 2012. 